\title{
Research Paper: The Effectiveness of Emotion-focused Group Therapy on the Reduction of Negative Emotions and Internet Addiction Symptoms
}

\author{
Mahdi Amini' ${ }^{1}$, Mozhgan Lotfi $^{*} \odot$, Reyhaneh Fatemitabar ${ }^{3}$, Leila Bahrampouri $\odot$ \\ 1. Department of Addiction, School of Behavioral Sciences and Mental Health (Tehran Institute of Psychiatry), Iran University of Medical Sciences, Tehran, Iran. \\ 2. Department of Mental Health, School of Behavioral Sciences and Mental Health (Tehran Institute of Psychiatry), Iran University of Medical Sciences, \\ Tehran, Iran. \\ 3. Department of Counselling, Sciences and Research Branch, Islamic Azad University, Tehran, Iran.
}

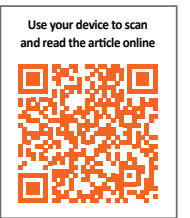

dration: Amini, M., Lotfi, M., Fatemitabar, R., \& Bahrampouri, L. (2020). The Effectiveness of Emotion-Focused Group Therapy on the Reduction of Negative Emotions and Internet Addiction Symptoms. Journal of Practice in Clinical Psychology, 8(1), 1-8. https://doi.org/10.32598/jpcp.8.1.1

https://doi.org/10.32598/jpcp.8.1.1

\section{Keywords:}

Emotion-focused Group Therapy (EFGT), Addiction, Internet addiction, Negative emotion

\section{ABSTRACT}

Objective: The relationship between emotional symptoms and addictive behaviors is essential. Moreover, short and effective interventions to treat these behaviors are required. Therefore, this study aimed to investigate the effectiveness of Emotion-Focused Group Therapy (EFGT) on the reduction of negative emotions and internet addiction symptoms.

Methods: This was an experimental study with a Pre-test-Post-test, and a control group design. The study participants included 40 students from the University of Bu-Ali-Sina in Hamedan City, Iran. They were selected by purposive sampling methods. The study participants were selected and randomly assigned to the experimental and control groups ( $\mathrm{n}=20$ for each group). The experimental group participated in 12 one-hour sessions of EFGT; however, the controls received no intervention. For data collection, the Internet Addiction Test (IAT) and thePositive and Negative Affect Schedule (PANAS) were used. Data analysis was performed using SPSS-.

Results: The obtained results have suggested that EFGT reduced negative emotions and the internet addiction symptoms (i.e. social problems, impact on performance, the lack of control, pathological use, and neglecting duties $)(\mathrm{P}<0.001)$. It also increased positive emotions $(\mathrm{P}<0.001)$.

Conclusion: Applying emotional strategies, as guidance in the clinical interview of internet addiction problems, with the use of emotional interventions, is recommended. Moreover, it could improve the clinical symptoms and increase the positive emotions, as a protective factor against the Internet addiction disorder.

\section{* Corresponding Author:}

Mozhgan Lotfi, PhD.

Address: Department of Mental Health, School of Behavioral Sciences and Mental Health (Tehran Institute of Psychiatry), Iran University of Medical Sciences, Tehran, Iran.

Tel: +98 (915) 3063345

E-mail: lotfei2007@gmail.com 


\section{Highlights}

- All strategies that people learn in EFGT could increase their health and affect their biopsychosocial and increasing their emotion regulation.

- Unpleasant emotions like loneliness, stress and sadness can be one of the causes of Internet addiction.

- EFGT is effective in increasing mental health and social interactions and reducing isolation and depression.

\section{Plain Language Summary}

Addiction is one of the most common problems in modern societies. One of the types of addiction is internet addiction, which involves excessive use of the Internet and leads to numerous problems in one's performance. Internet addiction has different consequences and affects everyone's lives. Internet addiction can be a behavioral response to unpleasant emotions that one experiences. Therefore, an appropriate treatment to cope with this phenomenon can be emotion-based therapy. In this treatment, people become more familiar with the nature of their emotions and learn how to deal with unpleasant emotions and accept them. In this study, researchers investigated the effectiveness of emotion-based group therapy on reducing negative emotions and symptoms of Internet addiction. The results of this study showed that emotion-based therapy can effectively regulate individuals' emotions and help reduce the negative feeling of people with internet addiction.

\section{Introduction}

ddiction is a social-global problem; extensive studies are annually conducted on this matter around the world (Fisher, Reynolds, \& Xandre, 2015; Ting-A-Kee, Heinmiller, \& van der Kooy, 2015; Samaha \& Hawi, 2016; Przepiorka \& Blachnio, 2016). Addiction, of any kind, is among the most critical causes of biopsychological, socio-cultural, interpersonal, and economic issues (Alam-mehrjerdi, Noori, \& Dolan, 2014; Stover, Hall, McMahon, \& Easton, 2012). A kind of addictions, i.e. referred to as the "post-modern abuse," is the Internet and computer games addiction (Goriup \& Arnuš, 2014). The Internet, like any other technology, brings many benefits to the development of societies with itself. However, Each person may be exposed to various Internet-based damages. Damage caused by the widespread use of the Internet is the impact of this technology on the human body and mind.

Moreover, with the ever-increasing use of this tool and the amount of time spent in cyberspace, users experience a false attachment, which is hard to disentangle from. Studies indicated that Internet Addiction Disorder (IAD) is associated with numerous physiological and psychological disorders.
Young (1998, quoted by Murali \& George, 2007) was the first to introduce the problematic and extreme use of the Internet as IAD. In his view, IAD is a broad term, including a wide range of behaviors and impulse control disorders.

Studies in the United States indicated that among Internet users, young people have the highest use. La Rose, Lin, and Eastin (2003) stated that the pathological use of the Internet reduces negative emotions, stress, loneliness, depression, and anxiety. Therefore, the pathological internet use is a multidimensional disorder that includes cognitive, emotional, and behavioral symptoms; it also causes life management problems in the addicted person. Symptoms of anxiety, depression, and isolation, etc. are emotional issues. Emotions are internal data that affect the stimulus and behaviors and maybe before cognition. Experimental data also suggested that emotion is controlled by the underlying structures of the cortex and can affect a range of cognitive processes, including attention bias, memory bias, judgment, and decision making. Emotions are a part of our everyday life; they have different effects on individuals' everyday life. Each of these emotions has a facilitating or inhibitory effect on various cognitive and behavioral functions. An ordinary person generally experiences a constant stream of moods. There are two types of negative and positive moods (Hashemi, Andalib Kouraeim, Pouresmali, \& Salehi Heydarabad 2011). Positive emotions include positive feelings, such 
as pleasure, pride, and joy. The negative emotions include negative feelings, such as stress, anxiety, sadness, anger, guilt, and shame. Therefore, people experiencing positive emotions are the ones with outward orientation and desirous of pleasure, rewards, joy, and so on. Contrarily, individuals with negative emotions are more prone to violence, fear, and anxiety.

Experiential processing therapy is an Emotion-Focused Therapy (EFT); it relates to the activation and reorganization of the emotional schema (Greenberg, 2017). The experiential processing therapy or the EFT combined with the humanistic-existential approach and strategies in cognitive doctrines brings together two conflicting views of empiricism and pragmatism; these are also based on the fact that "everything is in constant motion."

(Greenberg, 2017) described the emotional schema as an "internal organization and response that combines different information levels, including sensory-motor stimuli, emotional memory, and perceptual information all together." Unlike cognitive schematics, the emotional schema is a structure with non-verbal components and emotional experiences and reflects the combination of biology and experience in an individual. This approach assumes that helping clients to modify how they use their emotions to access it in purely empathic care and communicational manner can alter their emotional schema, i.e. subjected to problematic psychological functions (Akbari, 2015).

In Iran, studies on EFT have been strongly related to couples and couple therapies (Amani \& Mahdavi, 2013; Rajabi et al., 2015). However, some international studies were conducted on other samples (e.g. students), which mainly focused on reducing test anxiety and social anxiety (Akbari, 2015). The primary purpose of such interventions is to reduce negative emotions and increase positive ones. Furthermore, there is a direct relationship between emotional symptoms (positive and negative emotions) and IAD. Therefore, interventions focusing on emotions could increase positive emotions and reduce negative emotions; consequently, the severity of addiction to the Internet could be decreased.

The number of people with Internet addiction symptoms, addiction to the virtual world, as well as various Internet games, are growing. Thus, the present study investigated the effectiveness of Emotion-Focused Group Therapy (EFGT) on reducing negative emotions and the Internet addiction symptom and increasing emotional excitement in individuals with this disorder.

\section{Methods}

This was an experimental study with a Pre-test-Post-test and a control group design. The study population comprised all students at Bu-Ali-Sina University in Hamedan City, Iran with the symptoms of inclination towards the Internet and cyberspace. Moreover, 40 of them were selected by purposive sampling methods. In the first instance, the Internet Addiction Test (IAT) by Kimberly Young was distributed among 100 students. The students with scores ranging from 80 to 100 were considered as the study samples. They were then randomly divided into two experimental and control groups ( $\mathrm{n}=20$ for each group).

Additionally, 16 of 20 participants completed 12 weeks of EFGT. Intervention sessions were conducted by a trained and supervised Professor of Clinical Psychology. The study participants completed questionnaires at the beginning of the intervention, and a week after the end of it. Inclusion criteria were being university students, aged $>18$ years, not having severe psychiatric disorders, such as schizophrenia, bipolar disorder, and so on and having Internet addiction symptoms. The exclusion criteria included unwillingness to participate in the study, GERT is a 12-session intervention. In general, it consists of recognizing and introducing basic emotions in the group, familiarity with the primary and secondary objectives and tools, describing the experience and experience cycle, explaining the role of the language in expressing or reflecting emotion, and introducing a memorable evolutionary technique or visual experience, working with traumas, the emotional guidance of individuals on here and now, meeting the remaining feelings of emotion and calling them through other expressive techniques, strengthening algebraic and mental processes, preventing cognitive narratives, helping semantics, and discovering the agency's power in a new emotional experience.

\section{Questionniares}

Internet Addiction Test (IAT) is among the most authoritative tests for online addiction assessment, developed by Kimberly Young. This questionnaire has 20 questions and measures the severity of addiction to the Internet. This is a self-administered questionnaire and is based on the 6-point Likert-type scale 1. Strongly disagree; 2. Disagree; 3. Somewhat disagree; 4. Somewhat agree; 5. Agree; 6. Strongly agree (Alavi 2009). The scores obtained by each person will categorize them into three groups, as follows: 1. An ordinary Internet user; 2. A user who has faced problems using too much internet; 3. An Internet addict whom excessive use of internet has made him/her dependent on it and requires treatment. 
Positive and Negative Affect Schedule (PANAS) is 20 -item instrument assesses both aspects of the mood, the positive and negative emotions. Each subscale has 10 items. Items are ranked on a 5-point scale. This is a self-measurement instrument; by changing its instructions, we can use it to measure the emotional state and adjective aspects. This scale has favorable psychometric indices. The Cronbach's alpha coefficient for positive emotion ranges from 0.86 to 0.90 and for negative emotion, it ranges from 0.84 to 0.87 . Its coefficient of an 8 -week retest in a different time frame for positive emotion ranged from 0.47 to 0.68 . Moreover, for the negative emotion, the same value was reported to be from 0.39 to 0.71 .

The implementation of the research and the sampling initiated after obtaining approval from the University of Bu-Ali-Sina in Hamedan. To collect the required data, the researcher called for interested students to participate in the first stage of research. After reviewing the initial results, those with a higher score in the Internet addiction test were requested to attend the following sessions, if desired. The study participants were then randomly divided into the experimental and control groups.

The experimental group participated in 12 consecutive 2-hour treatment sessions of EFGT. Both groups completed the questionnaires at the beginning of the intervention and a week after the end of the treatment sessions. To observe research ethics, at the beginning of the research, while providing an adequate explanation to the participants, they were informed about the importance of the research, the study methodology, the duration of the interventions, the evaluation approach, and the confidentiality of the achieved information. They were also allowed to withdraw from the research at any stage. Considering the research design, to analyze the obtained data, descriptive statistics, Independent Samples t-test, and Analysis of Covariance (ANCOVA) were used. All analyses were performed using SPSS.

\section{Results}

The mean age of the experimental and control groups was 22.20 years (age range: 18-29 years) and 21.95 years (age range: 18-29 years), respectively. To examine the groups' homogeneity for age, Independent Samples t-test was used. The Independent Samples t-test results revealed no significant difference between the age of the two groups ( $\mathrm{t}=0.244, \mathrm{P}=0.808)$; thus, the two study groups were similar in age. The students' educational level was divided into three groups; associate, undergraduate, and postgraduate students. Comparing educational status in the two study groups using a Chi-squared test suggested no significant differences between the two groups regarding the educational level $\left(\chi^{2}=0.928 / 0, P \leq 150\right)$.

The statistical tests were performed for each group in two stages; before and after applying an independent variable. Descriptive statistics regarding the Pre-testPost-test scores of the dependent variables in the experimental and control group are presented in Table 1.

The mean post-test scores of internet addiction components decreased, compared to the Pre-test ones. However, there was no significant difference in the control group in this regard. The mean Post-test scores of positive and negative emotions have also decreased com-

Table 1. Descriptive statistics of Internet addiction in the experimental and control groups

\begin{tabular}{|c|c|c|c|c|}
\hline \multirow{3}{*}{ Variable } & \multicolumn{4}{|c|}{ Mean $\pm S D$} \\
\hline & \multicolumn{2}{|c|}{ Experimental Group } & \multicolumn{2}{|c|}{ Control Group } \\
\hline & Pre-test & Post-test & Pre-test & Post-test \\
\hline Social problems & $30.20 \pm 4.02$ & $25.70 \pm 6.03$ & $31.00 \pm 2.60$ & $30.40 \pm 5.21$ \\
\hline Impact on performance & $19.40 \pm 4.38$ & $18.73 \pm 2.64$ & $20.40 \pm 3.30$ & $20.80 \pm 1.56$ \\
\hline The lack of control & $28.65 \pm 2.56$ & $26.75 \pm 3.64$ & $28.90 \pm 2.02$ & $28.90 \pm 1.97$ \\
\hline Pathological use & $10.70 \pm 1.87$ & $7.45 \pm 3.63$ & $10.85 \pm 1.53$ & $10.80 \pm 1.28$ \\
\hline Neglecting duties & $11.7 \pm 02.52$ & $9.65 \pm 3.50$ & $12.20 \pm 2.95$ & $12.20 \pm 2.59$ \\
\hline Negative emotion & $30.80 \pm 1.61$ & $28.35 \pm 3.41$ & $30.65 \pm 1.42$ & $30.60 \pm 1.35$ \\
\hline Positive emotion & $20.80 \pm 5.43$ & $22.30 \pm 3.54$ & $26.35 \pm 1.93$ & $26.15 \pm 2.06$ \\
\hline
\end{tabular}


Table 2. ANCOVA results of Internet addiction symptoms in the study groups

\begin{tabular}{rccccc}
\hline & Value & F & df & Error df & Sig. \\
\hline Pillai's Trace & 0.429 & 4.364 & 5 & 29 & 0.001 \\
Wilks Lambda & 0.571 & 4.364 & 5 & 29 & 0.001 \\
Hoteling's Trace & 0.752 & 4.364 & 5 & 29 & 0.001 \\
\hline Roy's Largest Root & 0.752 & 4.364 & 5 & 29 & 0.001 \\
\hline
\end{tabular}

Table 3. ANCOVA results of negative and positive emotions and Internet addiction in the study groups

\begin{tabular}{ccccccc}
\hline Dependent Variable & $\begin{array}{c}\text { Sum of } \\
\text { Squares }\end{array}$ & df & $\begin{array}{c}\text { Mean } \\
\text { Squares }\end{array}$ & F & $\begin{array}{c}\text { Level of } \\
\text { Sig. }\end{array}$ & Effectiveness \\
\hline Social problems & 184.155 & 1 & 184.155 & 8.276 & 0.007 & 0.201 \\
\hline Impact on performance & 28.521 & 1 & 28.521 & 10.323 & 0.003 & 0.238 \\
\hline The lack of control & 34.546 & 1 & 34.546 & 17.537 & 0.000 & 0.347 \\
\hline Pathological use & 86.491 & 1 & 86.491 & 14.764 & 0.001 & 0.309 \\
\hline Neglecting duties & 40.664 & 1 & 40.664 & 11.301 & 0.002 & 0.255 \\
\hline Positive emotion & 56.418 & 1 & 56.418 & 6.680 & 0.014 & 0.157 \\
\hline Negative emotion & 84.429 & 1 & 84.429 & 14.262 & 0.001 & 0.284 \\
\hline
\end{tabular}

pared to the Pre-test values. To evaluate the effectiveness of therapy on Internet addiction and positive and negative emotion concerning the existence of a two-level independent variable (experimental and control groups), continuous dependent variables (the post-test scores of Internet addiction components and excitement), as well as confounding variables (the pre-test scores of Internet addiction and excitement components) were used for Multivariate Analysis of Covariance (MANCOVA). The relevant results are listed in Table 2.

The significance levels of all tests indicated a significant difference between the experimental and control groups at least in one of the dependent variables. The results of the effective factors on the difference between the study subjects are reported in Table 3.

As per Table 3, there was a significant difference between the mean values of social problems $(\mathrm{F}=8.27, \mathrm{P}$ $0.007)$, impact on the performance $(\mathrm{F}=10.32, \mathrm{P}=0.001)$, the lack of control $(17.53 \% ; \mathrm{F}=0.000, \mathrm{P}=0.001)$, pathological use $(\mathrm{F}=14.76, \mathrm{P}=0.001)$, and neglecting duties $(\mathrm{F}=11.30, \mathrm{P}=0.001)$ in the experimental and control groups. In general, EFGT has significantly reduced the score of social problems, impact on performance, the lack of control, pathological use, and neglecting duties.
Additionally, there was a significant difference between the experimental and control groups in the mean scores of positive emotion $(\mathrm{F}=14.56, \mathrm{P}=0.014)$ and negative emotions $(\mathrm{F}=14.26, \mathrm{P}=0.001)$.

\section{Discussion}

This study investigated the effects of EFGT on the reduction of negative emotions and Internet addiction symptoms. The obtained results suggested a significant difference between the experimental and control groups in the mean values of the components of Internet addiction (social problems, impact on performance, the lack of control, abuse and neglect of duties). Generally, EFGT has reduced Post-test scores of social problems, impact on the performance, the lack of control, pathological use, and neglecting duties. These results were consistent with those of Sepehri (2014), Fallahzadeh, Sanei and Farzad (2012), Javidi et al. (2014), Paivio et al. (2010), Acarturk et al., (2009).

Studies examining the EFT on Internet addiction are scarce. However, in research studies, there are various dimensions of emotion-based education for a wide range of psychiatric disorders that can be associated with Internet addiction. In this regard, Marhamati et al., (2007) has 
argued that EFT improves the mental health of female students.

Garnefski and Kraaij (2006) also believed that any emotional problem and the lack of adjustment could cause mental issues, like depression and anxiety. They believed that individuals' mental health results from the interaction between emotion-based strategies and a proper assessment of the stressful situation. Thus, EFGT is effective in increasing mental health and social interactions and reducing isolation and depression. Applying EFT to improve relationships can reduce Internet addiction. Evidence suggests that Internet addiction is caused by a lack of positive relationships with others. In other words, people with Internet addiction enter a cycle that can only improve their communication needs through the Internet. Numerous studies highlighted that emotionfocused education could improve the relationship with others and can develop social interactions. Therefore, the action mechanisms in the EFGT on Internet addiction occur through the same improvement in relationships.

Furthermore, all strategies people learn in EFGT could increase their health and affect their biopsychosocial and behavioral aspects, increasing their emotion regulation. These educations include strategies that make individuals more dynamic and prevent them from being inactive and surrendered to problems and dissatisfactions.

As a result, to reduce the negative feedbacks and to comfort themselves, they seek their interactive needs on the Internet and use it pathologically. According to Ciarrochi, Quartly-Scott (2001), positive and negative life events occur; thus, adjusting and managing emotions could control the social and communicative needs.Moreover, it would affect coping with them concerning a behavior without impulsivity. In addition, emotion regulation would cause less mental cost when facing a negative life event. Besides, in the face of positive events, more advantages will be taken. This enables the individual to act more effectively in interaction with their environment using emotional regulation; this is what Internet addicts are deprived from. They often negatively interact with the social environment.

Furthermore, the obtained results indicated a significant difference in the mean values of positive and negative emotions between the study groups. Generally, based on these findings, it can be said that emotion-focused group therapy has decreased negative emotions and increased emotions in the post-test. These results are consistent with those of Sepehri (2014), Fallahzadeh, Sanei \& Farzad (2012) The results of Akbari (2015), Amani and Maghzubi (2013); Javidi et al. (2014); Actertok, et al. (2009); Paivio et al. (2010), Paivio and Nieuwenhuis (2001).

The literature on emotion-based therapy reflects that this method has been used in numerous ways concerning communicational and emotional problems. In addition, EFT is effective in emotional adaptability. As a result, the nature of emotion-focused strategies helps individuals with their interpersonal interactions. In emotionalfocused strategies, individuals seek direct guidance for their spontaneous emotions. Accordingly, emotion is considered as valued (negative and negative) reactions of individuals towards events concerning their constant stress. In this sense, emotion consists of several components, including specific thoughts and feelings in response to behavioral and physiological reactions. Inevitably, there is a relationship between educating emotion-focused strategies and its related structures, such as mood regulation, anger management, and managing relationships. Emotion-based therapy is comprehensive and involves the regulation of specific emotions, such as anger, fear, moods, and all sorts of affective reactions. Therefore, in social relationships, emotional-focused education can cover various dimensions and significantly impact relationships.

Many of the early behaviors of individuals that might lead to conflicts and incompatibilities might be caused by emotional reactions (i.e. initial emotional reactions) The initial emotional response relates to a rapid reaction without the individual's experience of emotional events. The secondary response relates to the individual's ability to overcome the initial emotional response.This could explain how emotion-focused education increases positive emotion and reduces negative emotions. The initial emotional response of individuals indicates their uncontrolled and rapid emotional response. The initial reaction will be successful with the second emotional response,i.e. caused by the response to emotional-based therapy. Transmission from the primary to secondary response can improve many immature behaviors caused by the initial response. This process could also increase positive emotions and reduce negative ones.

Therefore, emotion-focused education could provide a person with emotional self-regulation. When people can control, regulate, and manage their emotions, they can compare their current emotional state with the desired one; accordingly, they could adopt appropriate steps toward the desired emotional state. This reduces the emotional damage and consequently reduces Internet addiction symptoms, as psychological damage. Besides, 
EFGT can be used as an effective way in the treatment and prevention of the Internet and cyberspace addiction symptoms.

The present study had some limitations that should be considered in future studies. One such limitation was the use of questionnaires only to collect data. This may affect the contributions of the participant, or individuals may not answer some of the questions correctly to provide a better picture of themselves. Another limitation was the lack of assessment in the follow-up phase. Thus, the definitive opinion on the long-term impact of treatment cannot be ruled out.

\section{Conclusion}

EFGT effectively reduced negative emotions and Internet addiction symptoms; thus, it can be used as an effective approach in this field. To make it more functional and to reduce costs, this approach can also be used in a group. It is recommended that educational packages be produced and made available for use by families, students, therapy centers, etc. based on this approach. Finally, consultants and therapists are recommended to take guidance from emotional strategies when identifying the problems associated with Internet addiction. This could increase the effectiveness of their treatment and provide effective strategies to the clients by identifying their ineffective strategies.

\section{Ethical Considerations}

\section{Compliance with ethical guidelines}

All ethical principles were considered in this article. The participants were informed about the purpose of the research and its implementation stages; they were also assured about the confidentiality of their information; Moreover, They were allowed to leave the study whenever they wish, and if desired, the results of the research would be available to them.

\section{Funding}

This research did not receive any specific grant from funding agencies in the public, commercial, or not-forprofit sectors.

\section{Authors' contributions}

participated in designing the study, literature review, clinical evaluation and performing the experiments: Mahdi Amini and Mozhgan Lotfei; participated in writ- ing the manuscript: Leila Bahrampoori; participated in acquisition of data and interpreting the data and analyzed data: Reyhaneh Fatemitabar.

\section{Conflict of interest}

The authors have no conflict of interest.

\section{References}

Abadi, H., \& Soltanifar, M. (2012). The effectiveness of Emotion-Focused Therapy (EFT) on the marital adjustment and positive emotion of couples with extra-marital relationships. Research-Supported Psychological Treatments, 1(2), 32-8.

Acarturk, C., Cuijpers, P., Van Straten, A., \& De Graaf, R. (2009). Psychological treatment of social anxiety disorder: A metaanalysis. Psychological Medicine. Cambridge University Press, 39(2), 241-54. [DOI:10.1017/S0033291708003590] [PMID]

Akbari, Alah H. (2015). The effectiveness of treatment strategies processor-experience (emotion-focused) on reducing the exam anxiety of high school student. Journal of Educational Psychology,11(37), 187-205.

Alam-mehrjerdi Z, Noori R, Dolan K. (2016). Opioid use, Treatment and Harm Rreduction Services: The First Report from the Persian Gulf Region. Taylor \& Francis, 21(2), 217-23.

Coyne, S. M., Dyer, W. J., Densley, R., Money, N.M., Day, R.D. \& Harper, J. M. (2015). Physiological indicators of pathologic video game use in adolescence. Journal of Adolescent Health 56(3), 307-13. [DOI:10.1016/j.jadohealth.2014.10.271] [PMID]

Fallahzadeh, H., Sanaei, Z.B., Farzad, V. ( 2013). A study on the effectiveness of emotionally focused couple therapy and integrated systemic couple therapy on reducing intimacy anxiety. Journal of Family Research, 4(32), 456-84.

Fisher, D. G., Reynolds, G. L., \& Xandre, P. (2015). Trichomonas vaginalis infection and drug abuse risk for women. Drug and Alcohol Dependence, 5(12), e68-9. [DOI:10.1016/j.drugalcdep.2015.07.1105]

Goriup, J., \& Arnuš, A. (2014). Some sociological, medical and legislative views on video game addiction (A slovenian case study). Acta Educationis Generalis, 4(1); 25-40. [DOI:10.1515/ atd-2015-0010]

Goldman, R. N., Greenberg L. S. (2007). Integrating love and power in emotion-focused couple therapy. European Association for Psychotherapy, 7(1), 117-35.

Greenberg, L., S. (2004). Emotion-focused therapy: Clin Psychol Psychother. Wiley Online Library, 11(1), 3-16. [DOI:10.1002/ cpp.388]

Greenberg L. S. (2017). Using emotions as a pathway for change. Psyccritiques, 52(33), 315-18.

Hashemi, T., Andalib Kouraeim, M., Pouresmali, A., \& Saleh Heydarabad, M. (2011). Effect of inducing mood on cognitive and behavioral performance. Iranian Journal of Medical Education, 4(3), 101-5. 
Javidi, N. A., Soleimani, A., Ahmadi, K., \& Samadzadeh, M. (2014). The effectiveness of Emotion-focused Couple Therapy (EFCT) on improving the couple's communication patterns. International Journal of Behavioral Sciences, 11(5):402-10.

Murali, V., \& George, S. (2007). Lost online: An overview of internet addiction. Advances in Psychiatric Treatment, 13(1), 2430. [DOI:10.1192/apt.bp.106.002907]

Paivio, S. C., \& Nieuwenhuis, J. A. (2001). Efficacy of emotion focused therapy for adult survivors of child abuse: A preliminary study. Journal of Traumatic Stress, 14(1), 115-33. [DOI:10.1023/A:1007891716593]

Przepiorka, A., \& Blachnio, A. (2016). Time perspective in Internet and Facebook addiction. Computers in Human Behavior, 60, 13-8. [DOI:10.1016/j.chb.2016.02.045]

Ranjbari, M. (2014). The effectiveness of Emotion-Focused Couple Therapy (EFCT) in comparisson with Solution-Focused Couple Therapy (SFCT) on dysfunctional marital happiness and attitudes communication. Mashhad: Mashhad Ferdowsi University.

Samaha, M., \& Hawi, N. S. (2016). Relationships among smartphone addiction, stress, academic performance, and satisfaction with life. Computers in Human Behavior, 57, 321-325.

Sepehri, S. The effectiveness of structured group therapy education in comparisson with Emotion-focused Therapy on the Perfectionism and Defensive Mechanism of Married Women with Fear of Intimacy [Internet]. Mashhad Ferdowsi University; 1393. Available from: https://ganj-old.irandoc.ac.ir/ articles/693744

Soudani, M., Karimi, J., Mehrabi-zadeh Honarmand, M., \& Neisi, A. (2014). Comparison of the effectiveness of the two univariate couple therapy and emotional-focused couple therapy on the symptoms of Depression and Post-Traumatic Stress due to Extra-Marital Relationships Among Couples. Clinical Psychology, 19(3).

Stover, C., S., Hall, C., McMahon, T., J., \& Easton, C., J. (2012). Fathers entering substance abuse treatment: An examination of substance abuse, trauma symptoms and parenting behaviors. Journal of Substance Abuse Treatment, 43(3):335-43. [DOI:10.1016/j.jsat.2011.12.012] [PMID] [PMCID]

Ting-A-Kee, R., Heinmiller, A., van der Kooy, D. (2015). A proposed resolution to the paradox of drug reward: Dopamine's evolution from an aversive signal to a facilitator of drug reward via negative reinforcement. Neuroscience \& Biobehavioral Reviews, 56, 50-61. [DOI:10.1016/j.neubiorev.2015.06.016] [PMID]

Amani, R., \& Majzoobi, M. R. (2013). Comparing Effectiveness of Emotional Focused, Cognitive Behavioral and Cognitive Behavior Emotional Couple Therapy on the Change Process of Spouses' Marital Satisfaction and Women Depression. Semiannual Journal of Family Counseling and Psychotherapy, 3(3).

Ciarrochi J, \& Quartly-Scott, G. (2006). The link between emotional competence and well-being: a longitudinal study. British Journal of Guidance \& Counselling, 34(2), 231-43.

Greenberg, L. S., \& Pascual-Leone, A. (2006). Emotion in psychotherapy: a practice-friendly research review. Journal of Clinical Psychology, 62(5), 611-630. [doi: 10.1002/jclp.20252]

H. Falahzade, B. Sanai Zaker , \& Farzad, V. (2013). A study on the effectiveness of emotionally focused couple therapy and integrated systemic couple therapy on reducing intimacy anxiety. Journal of Family Research, 4(32), 465-84.

Paivio, S.C. \& Nieuwenhuis, J. A. (2001). Efficacy of emotionally focused therapy for adult survivors of child abuse: A preliminary study. Journal of Traumatic Stress, 14(1), 115-33.

Paivio, C., Sandra, L., Jarry, J., Chagigiorgis, H., Hall, I., \& Rastlon, M. (2010). Efficacy of two version of emotion focused therapy for resolving child abuse trauma. Psychotherapy Research, 20(3):353-66. [doi: 10.1080/10503300903505274]

Garnefski, N., Kraaij, V. (2001). Cognitive Emotion Regulation Questionnaire- development of a short 18- item version (CERQ- short). Personality and Individual Difference, 41, 104553

LaRose, R., Lin, C. A., \& Eastin, M. S. (2003). Unregulated Internet Usage: Addiction, Habit, or Deficient Self-Regulation? Media Psychology, 5(3), 225-53. 